\title{
A large left atrial lipoma combined with coronary artery disease
}

\author{
Yun Liu, Xiaomei Zheng, Yu Du, Zhicheng Zhu, Tiance Wang, Rihao Xu, Dan Li and Kexiang Liu*
}

\begin{abstract}
Background: Primary benign tumors of the heart are extremely rare and usually difficult to diagnose for their asymptomatic signs

Case presentation: A 66-year-old woman was admitted for shortness of breath caused by a large left atrial lipoma combined with coronary artery disease. Next, we successfully performed simultaneous curative surgery for the large cardiac lipoma and coronary artery bypass grafting with a "starfish" and no cardiopulmonary bypass was used.The patient was discharged on the eighth postoperative day in a good condition, and has remained asymptomatic at the 5-month follow-up.

Conclusions: Lipomas are rare and difficult to diagnose, while computed tomography and computed tomography angiography can give us very important clues. Surgery is necessary. We can introduce a "starfish"to the operationand the cardiopulmonary bypass is unnecessary for the left lipoma with coronary artery disease.
\end{abstract}

Keywords: Lipoma, Cardiac benign tumor, Coronary artery bypass

\section{Background}

Cardiac lipomas are extremely rare, accounting for $8.4 \%$ of all primary tumors [1] and found at a frequency of only $0.001 \%-0.28 \%$ at autopsy [2]. They are frequently located in the left ventricle or right atrium. Left artrial lipomas are very rare with only 3 references in all of the epicardiac lipomas [3]. Clinically, this tumor is asymptomatic and found incidentally in the vast majority of cases [4]. Only large left atrial lipomas could alter atrial and ventricular functions and result in dyspnea, such as in our case.

\section{Case presentation}

A 66-year-old female was admitted because of dyspnea. On admission, the temperature was normal, the pulse was 67 $/ \mathrm{min}$, the respiration rate was $20 / \mathrm{min}$ and the blood pressure was 108/68 mmHg. Laboratory examinations were normal. Computed tomography (CT) showed that a large low density mass located behind the posterior wall of the left atrium. The left atrium was compressed. The mass showed a density similar to adipose tissue and was not enhanced on computed tomography angiography(CTA) (Fig. 1). We

\footnotetext{
* Correspondence: kxliu64@hotmail.com

The Second Affiliated Hospital of Jilin University, Changchun, China
}

highly suspected that it was a lipoma on the basis of its CT manifestations. The ejection fraction was $62 \%$. The electrocardiogram was normal. Considering of her age, the coronary angiography was performed and the result revealed a $70 \%$ stenosis in the left anterior descending (LAD) branch. And we decided to perform simultaneous curative surgery for the cardiac lipoma and coronary artery bypass grafting (CABG).

A median sternotomy and pericardial incision were performed undergeneral anesthesia. After we lifted up the heart with a "starfish", a soft, yellow tumor which originated from the left atrium without any invasion to the pericardium was found (Fig. 2). Then we excised the basal part of the tumor carefully with an electrome and no cardiopulmonary bypass was used. The mass was removed completely and measured about $8 \mathrm{~cm} \times 8 \mathrm{~cm} \times 4 \mathrm{~cm}$ (Fig. 3). Next, we performed the anastomosis between the anterior descending branch and the left internal mammary artery. The procedure was smooth, and postoperative recovery was good.

The histopathological examination revealed mature adipocytes confirming our suspicion of a limopa (Fig. 4). The patient was discharged on the eighth postoperative day in a good condition, and has remained asymptomatic at the 


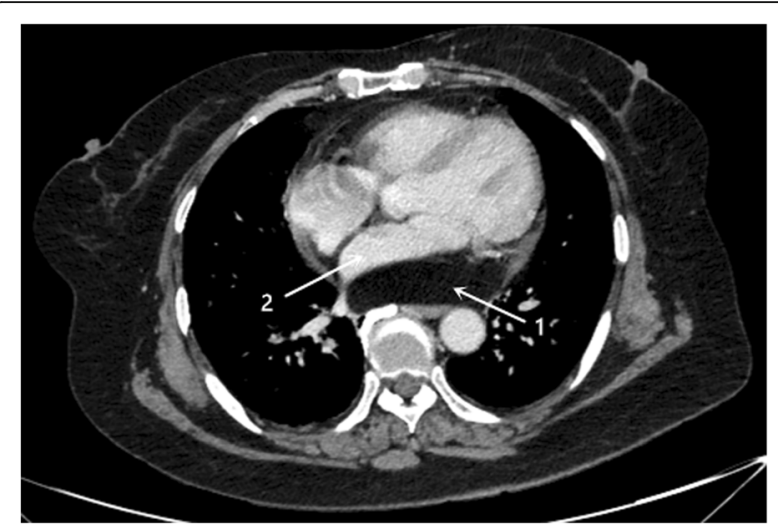

Fig. 1 CTA showed that a large low density mass located on the posterior wall of the left atrium. The left atrium was compressed. The tumor was not enhanced on CTA (1. Tumor,2. Left atrium)

5-month follow-up. Echocardiography (ECHO) detected no signs of recurrence.

\section{Discussion}

It's usually difficult to diagnosis left arterial lipomas for its asymptomatic and low incidence. However, CT/CTA can give us very important clues to the diagnosis. When the CT showed a fat-like low density mass under the epicardium and was not enhanced on CTA, we should

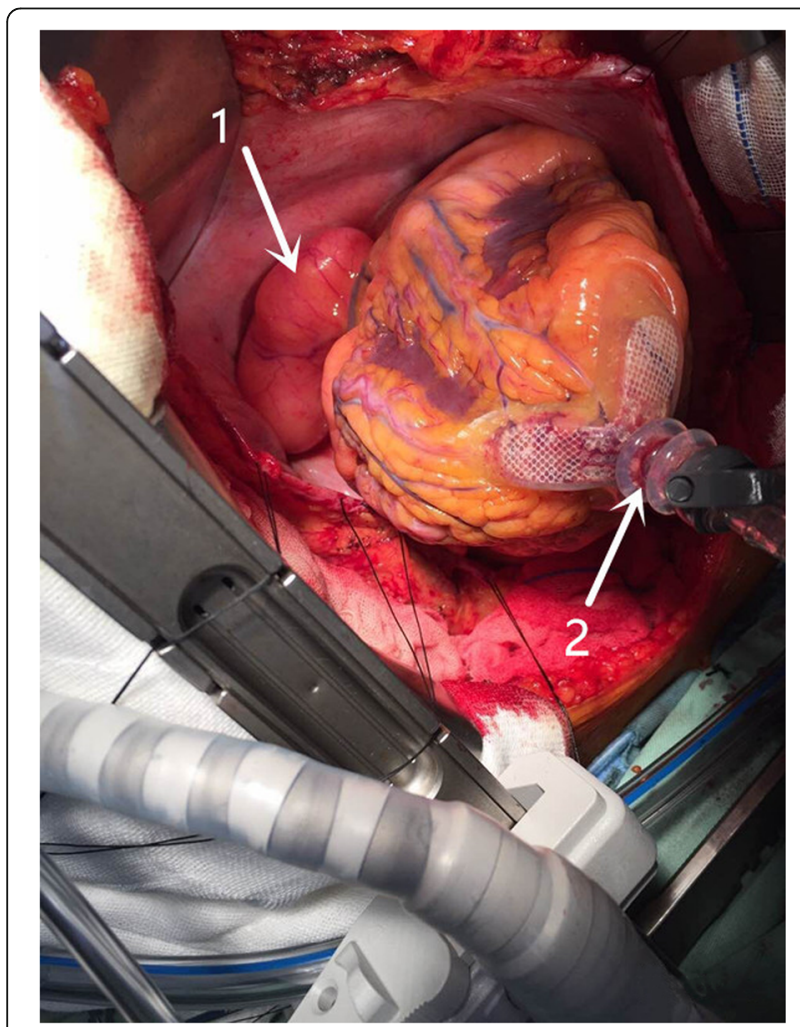

Fig. 2 Intraoperative view of the tumor. A large lipoma was seen at thoracotomy with a starfish.(1.lipoma; 2.starfish)

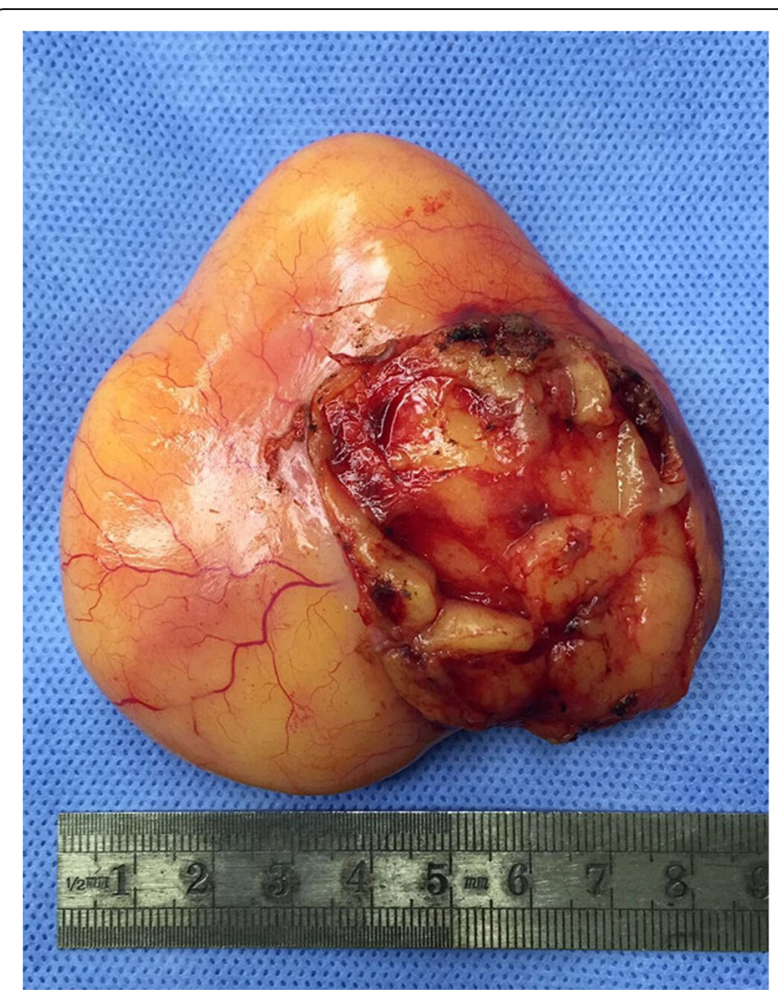

Fig. 3 The mass was attached to the posterior pericardium beneath the left pulmonary artery with a stalk connected to the left atrium

consider it as a lipoma first. Cardiac lipomas are benign and slowly growing, but for large lipomas, surgical resection is necessary to prevent tumor compression syndromes.

As we know, in all of the three cases, cardiac surgeons in one case performed the resection of the tumor and repaired left atrium(LA) surface with an autologous pericardial patch under cardiopulmonary bypass. In the other two cases, cardiac surgeons removed the tumor

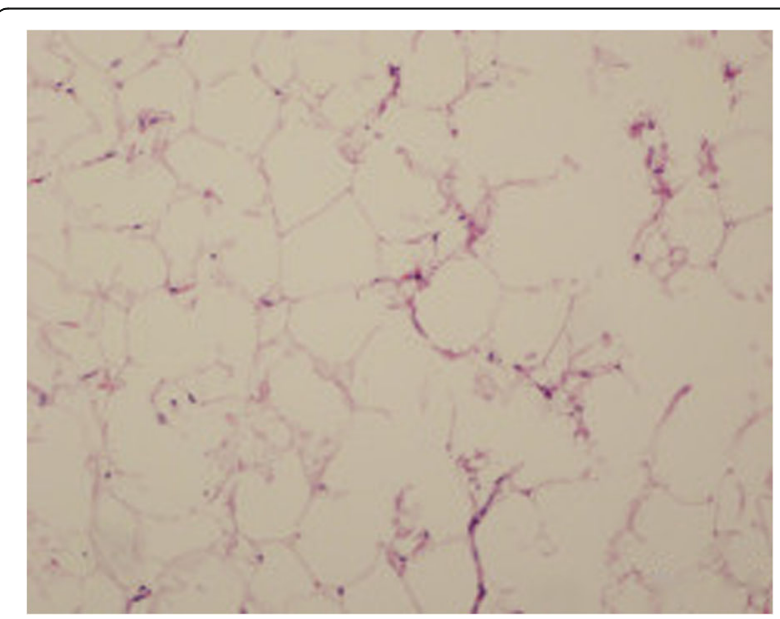

Fig. 4 The histopathological examination revealed mature adipocytes 
directly without cardiopulmonary bypass. In this case, we used a "starfish" to lift up the heart, which made the lipoma exposed well and removed easily. Also we underwent the off-pump coronary aortic bypass grafting (OPCABG). The result was good. So we consider that it's unnecessary to perform the surgery under cardiopulmonary bypass for the left atrial lipoma pateints with coronary artery diseases.

\section{Conclusion}

Lipomas are rare and difficult to diagnose, while computed tomography and computed tomography angiography can give us very important clues. Surgery is necessary. We can introduce a "starfish" to the operation and the cardiopulmonary bypass is unnecessary for the left lipoma with coronary artery disease.

\section{Abbreviations}

CABG: Coronary artery bypass grafting; CPB: Cardiopulmonary bypass;

$\mathrm{CT}$ : Computed tomography; CTA: Computed tomography angiography;

ECHO: Echocardiography; LA: Left atrium; LAD: Left anterior descending;

OPCABG: Off-pump coronary aortic bypass grafting

\section{Acknowledgements}

Not applicable

\section{Funding}

No funding sources

\section{Availability of data and materials}

Data sharing not applicable to this article as no datasets were generated or analysed during the current study

\section{Authors' contributions}

$K X L$ designed the study, performed the operation, and revised the manuscript critically. LY collected the date and wrote the article. XMZ and DY referred to the related literature. All authors read and approved the final manuscript.

Ethics approval and consent to participate

Not applicable

\section{Consent for publication}

Not applicable

\section{Competing interests}

The authors declare that they have no competing interests.

\section{Publisher's Note}

Springer Nature remains neutral with regard to jurisdictional claims in published maps and institutional affiliations.

Received: 24 March 2017 Accepted: 2 August 2017

Published online: 22 August 2017

\section{References}

1. Khoueiry G. Nidal a, BiRafeh.Left atrial appendage lipoma: an unusual location of cardiac lipomas. Echocardiography. 2011;28:E91-3.

2. Wilson S, Frederick J, Braunwald E. Primary tumors of the heart. In: Braunwald $\mathrm{E}$, editor. Heart disease. A textbook of cardiovascular medicine. 5th ed. Philadelphia: Saunders; 1997. p. 1464-77.

3. Hayashi H, Hidaka F. A left ventricular lipoma diagnosed on threedimensional electrocardiogramgated cardiac computed tomography. Heart Vessel. 2008;23:366-9.

4. Georges K, Nidal AR. A case of massive left atrial lipoma occupying pericardial space. Jpn Heart J. 2004;45:715-21.

Submit your next manuscript to BioMed Central and we will help you at every step:

- We accept pre-submission inquiries

- Our selector tool helps you to find the most relevant journal

- We provide round the clock customer support

- Convenient online submission

- Thorough peer review

- Inclusion in PubMed and all major indexing services

- Maximum visibility for your research

Submit your manuscript at www.biomedcentral.com/submit 